\title{
Increasing Graduate Medical Education (GME) in Critical Access Hospitals (CAH) Could Enhance Physician Recruitment and Retention in Rural America
}

\author{
Imam M. Xierali, PhD, Sarah A. Sweeney, BS, Robert L. Phillips, Jr., MD, MSPH, \\ Andrew W. Bazemore, MD, MPH, and Stephen M. Petterson, PhD
}

Critical Access Hospitals (CAHs) are essential to a functinoning health care safety net and are a potential partner of rural Graduate Medical Education (GME) which is associated with greater likelihood of service in rural and underserved areas. Currently very little Medicare funding supports GME in the CAH setting, highlighting a missed opportunity to improve access to care in rural America. (J Am Board Fam Med 2012;25:7-8.)

Figure 1. Number of Critical Access Hospitals reporting intern and resident full-time equivalents.

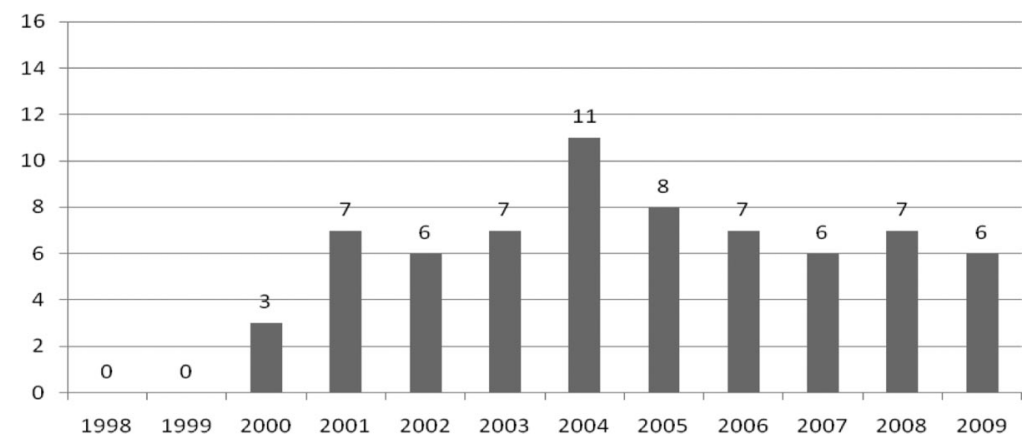

Critical Access Hospitals (CAHs) are geographically isolated, small rural hospitals that are typically the sole source of care for their community, providing not only acute care but a broad spectrum of basic

This article was externally peer reviewed.

Submitted 1 June 2011; revised 7 September 2011; accepted 14 September 2011.

From the Robert Graham Center for Policy Studies in Family Medicine and Primary Care, Washington, DC (IX, $\mathrm{RP}, \mathrm{AB}, \mathrm{SP}$ ); and the Case Western Reserve University School of Medicine, Cleveland, OH (SS).

Funding: This research was conducted by the Robert Graham Center under contract to the Office of Rural Health Policy contract no. R04RH15123, Rockville, MD.

Conflict of interest: none declared.

Disclaimer: No statement may be construed as the official position of the Office of Rural Health Policy of the U.S. Department of Health and Human Services.

Corresponding author: Imam M. Xierali, PhD, the Robert Graham Center for Policy Studies in Family Medicine and Primary Care, 1350 Connecticut Avenue, Suite 201, Washington, DC 20036 (E-mail: IXierali@aafp.org). health services. There was a robust increase of CAH designations from 50 in 1998 to 1,310 in 2009.

Rural communities struggle to recruit and retain health care providers. In 2008, $81 \%$ of rural counties were or contained areas designated as Primary Care Health Professional Shortage Areas. ${ }^{1}$ Encouraging evidence shows that residents trained in a rural setting are much more likely to continue to serve in rural or underserved settings. ${ }^{2,3}$ Analysis of Medicare hospital cost report data suggests that very few CAHs ever have reported intern and resident training (see Figure 1). As rural hospitals and as hospitals without prior graduate medical education (GME) programs, CAHs are eligible for starting or becoming funded members of GME training programs.

Increasing the capacity for CAHs to create and expand training programs could improve access to care in rural communities and strengthen existing rural training programs, many of which are threatened or closing. Recent policies promoting 
primary care training, such as the teaching health center program, also mean opportunity for CAHs to play an important role in GME expansion. Though this role for $\mathrm{CAHs}$ requires no legislative changes, CAHs will face additional hurdles related to accreditation and staffing.

The authors would like to thank Drs. Frederick Chen, Mark Doescher, and Randall Longenecker for their kind discussion of the brief.

\section{References}

1. Health Resources and Services Administration Geospatial Data Warehouse. Primary Care Health
Professional Shortage Areas. http://datawarehouse. hrsa.gov. Accessed August 15, 2008.

2. Chen F, Fordyce M, Andes S, Hart LG. Which medical schools produce rural physicians? A 15 -year update. Academic Medicine 2010;85(4):594-8.

3. Phillips RL, Dodoo MS, Petterson S, et al. Specialty and geographic distribution of the physician workforce: what influences medical student \& resident choices? March 2, 2009. Washington, DC: The Robert Graham Center. Available at http://www. graham-center.org/online/etc/medialib/graham/ documents/publications/mongraphs-books/2009/ rgcmo-specialty-geographic.Par.0001.File.tmp/ Specialty-geography-compressed.pdf. Accessed November 14, 2011. 